colloquial licentiousness". The latter example will be familiar to Scottish and Irish doctors, to whom 'boke' or 'bauk' means to be sick, or (the 'dry boke') to retch. I suspect that the angry dishthrowing subject would have been of German or Jewish extraction, since their 'geshinker' neologism is a contraction of two words - the German 'Geschirr', meaning dishes, and the English 'sink'. To use Freud's formulation (1916), this represents "a condensation accompanied by the formation of a substitute". Although it wouldn't please Johnson, such condensations are familiar to us all, and are usually readily understandable within their own cultural context. Far from demonstrating an objectively assessed and phenomenologically pure 'language error', these examples emphasise the rigidity of linguistic approaches, and undermine the idea that speech could exist 'independent of thought' in a cultural, developmental or emotional vacuum.

So how are we to pursue a study of 'communication disorder'? Harre \& Gillett (1994) emphasise the close link between the "use of language and the concepts in which thoughts are articulated". It is specious to separate speech and thought; we should rather pursue the 'meaning of the meaning' coded in words. Vygotsky (1962) showed that childrens' cognitive development takes place in a conversational context, but that the formation of language goes beyond simply learning to speak: "the sign is the word which first plays the role of means in forming a concept, and later becomes its symbol" "the system of signs [or words] restructures the whole psychological process". Purely linguistic approaches to discursive phenomena such a 'manner and relevance' are inadequate to the task; 'speech acts' (Harre \& Gillett, 1994) might be a better way of interpreting how we "direct our mental operations, control their cause and channel them towards the solution of the problem confronting us" (Vygotsky, 1962).

There is more to speech and thought than simply communication: 'thought disorder' remains a useful and appropriate psychiatric concept.

FreUD, F. (1916) Jokes and their Relation to the Subconscious. (1976; ed A. Richards) Pelican.

Harre, R. \& GILlett, G. (1994) The Discursive Mind. Sage.

Jornson, S (1775) Preface to the Dictionary.

Vycotsky, L. S. (1962) Language and Thinking, p. 280 (1972; ed P. Adams). Penguin.

Wrttgenstenn, L. (1958) Blue and Brown Books, p. 1. Oxford: Blackwell.

Parkhead Hospital

M. SMTrH

81 Salamanca Street

Glasgow G31 5BA
SIR: We write to express our reservations about one of the examples of neologism in Thomas's paper on thought disorder (BJP, March 1995, 166, 287-290),

"So I sort of bawked the thing up."

In the Scottish National Dictionary one can find the word 'bowk', meaning 'to retch'. Variants of it can be found in the Oxford English Dictionary and Wright's English Dialect Dictionary, with spellings including 'bolk', 'boke' and 'bawk', meaning "to vomit, to retch or make efforts as in vomiting". In Wright's it is described as being found in Scots, Irish and Northumbrian dialects, while the OED attributes its origins to Middle English.

In the context of the fragment of speech quoted, 'bawked' would appear to represent an error in transcription of a word which would make perfect sense to someone who spoke one of these dialects. As it is a word whose derivation can be understood, it is not a neologism, but an example of the richness of regional dialect. It would be most likely to be understood by a Scot, although Scots dialect frequently becomes incorporated into the English language and gains wider usage.

This example highlights the difficulties that can arise in interviewing people who speak regional dialects or other languages. Just because a word is not familiar does not mean that it is necessarily a neologism. It also serves as a timely reminder, with regional assemblies being a matter of debate at the moment, that the principles of trans-cultural psychiatry apply within the UK.

I. C. Macmillan

Royal Victoria Infirmary

Newcastle upon Tyne NE1 4LP

David Rice Hospital

R. M. Wales

Drayton Road

Norwich NR6 SBE

\section{Chlorpromazine-induced retinopathy}

SIR: It has been known for some time that phenothiazines may cause a diffuse pigmentary retinopathy. This is particularly so for phenothiazines with a piperidine side chain, such as thioridazine. Piperidines with aliphatic side chains such as chlorpromazine are much less likely to cause ocular complications although a number have been described previously (Reynolds, 1993).

The previous reports of chlorpromazine-induced retinopathy have been related to doses above $800 \mathrm{mg}$, for greater than 20 months (Spiteri \& James, 1983). 
We report the case of a young man who developed permanent retinal changes leading to blindness as a result of chlorpromazine. It is particularly unusual as he received only very low doses of chlorpromazine and was poorly compliant.

\section{Case report}

SW is a 33-year-old male with a chronic schizophrenic illness. He first presented at the age of 19 with psychotic symptoms thought to be hallucinogen induced which settled quickly on very low dose chlorpromazine. Later that year he was readmitted and attracted a diagnosis of schizophrenia. Over the next nine years he received only very low doses of chlorpromazine (max $200 \mathrm{mg}$ daily) and a short course of fluphenazine decanoate $(25 \mathrm{mg}$ four-weekly), but was very poorly compliant.

In 1992 he complained of poor vision, so was referred to an ophthalmologist where he was found to have greatly reduced visual acuity, grossly limited perimetry, bilateral proptosis, and fluorescein angiography revealed bilateral macular oedema. Extensive investigations performed were negative and chlorpromazine-induced retinopathy was diagnosed. Despite discontinuing chlorpromazine permanent retinal pigment epithelial damage was present at both foveas. He remained functionally impaired and was registered blind, and is seeking damages.

It would therefore seem prudent that clinicians are aware that chlorpromazine may cause severe ocular damage even at low dose. There may also be a case for screening for pigmentary retinopathy in patients who are exposed to chlorpromazine.

ReYNoLDS, J.E.F. (1993) Martindale - The Extra Pharmacopoeia (30th edn). London: The Pharmaceutical Press.

SPITERI, M. A. \& JAMES, D. G. (1983) Adverse ocular reactions to drugs. Postgraduate Medical Journal, 59, 343-349.

A. C. MrtChelL K. W. BROWN

Bellsdyke Hospital

Larbert FK5 4SF

\section{Buspirone augmentation of sertraline}

SIR: Refractory obsessive-compulsive symptoms are vexatious for both patient and clinician (Jenike \& Rauch, 1994). In the considerable number of cases which fail to respond to SSRIs, augmentation strategies with lithium or buspirone have been disappointing (Dominguez \& Mestre, 1994). After observing incomplete responses to sertraline, I report two cases of dramatic symptomatic improvement with the addition of buspirone.
Case 1 is a bus driver in his early twenties, with a 5-6-year history of obsessive-compulsive disorder. When unwell, he is unable to work, as he becomes preoccupied with checking his cash float and his schedules to the extent that his route runs progressively later and later. Having been suicidal, his OCD was originally mistaken for depression. Treatment with dothiepin and desipramine had been unhelpful, diazepam relieved his anxiety but not the rituals. After his diagnosis two years previously, he responded partially to fluoxetine (20-40 mg/day), but discontinued this due to persistent insomnia, headache and lethargy. Sertraline was somewhat better tolerated, but nausea became a problem each time the dose was pushed above $100 \mathrm{mg} / \mathrm{day}$. At this dose his improvement was partial (Y-BOCS reduced from 28 to 20; Zung from 60 to 50); he was able to work (barely) but was tense and exhausted from struggling against his rituals. Addition of buspirone $10 \mathrm{mg} /$ day was dramatically effective within days (YBOCS 8; Zung 27), without any return of his nausea. Attempts to withdraw sertraline or buspirone have been equally unsuccessful, due to the rapid return of his anxiety and rituals. He has remained well on this combination for 15 months.

Case 2 is a 36-year-old woman with a 20-year history of recurrent anorexia nervosa, OCD, migraine, and marked premenstrual irritability. She had responded poorly to various tricyclic antidepressants, and was unable to tolerate more than $75 \mathrm{mg}$ of clomipramine. Her OCD was particularly debilitating; apart from rarely finishing her rituals before $2 \mathrm{am}$, she felt driven to arrange coloured clothes pegs 'properly' in order to protect her children from harm. Phenelzine $60 \mathrm{mg} /$ day was effective in prophylaxis of her migraine and premenstrual mood change, but did not affect her OCD and was finally rejected because of its stimulation of appetite and weight gain. Fluoxetine was effective in partially suppressing her OCD, but worsened her headaches and was abandoned. Sertraline was less likely to aggravate her migrane, but was incompletely effective up to $200 \mathrm{mg} /$ day with marked symptoms persisting (Y-BOCS 25; Ham-D 31).

Addition of buspirone up to $60 \mathrm{mg} /$ day produced a dramatic remission of her compulsions and premenstrual dysphoria, her obsessions remaining largely unchanged (Y-BOCS 17; Ham-D 12). Her headaches, worsened by this combination, were relieved by the addition of atenolol. Attempts to withdraw sertraline or buspirone were quickly abandoned due to recrudescence of compulsive 